Article

\title{
Comparison of Bone Regeneration between Porcine-Derived and Bovine-Derived Xenografts in Rat Calvarial Defects: A Non-Inferiority Study
}

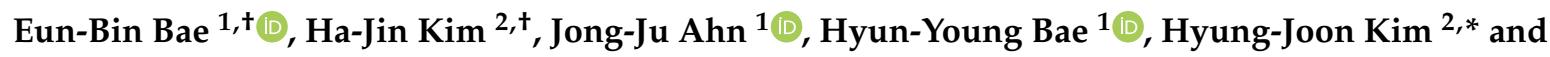 \\ Jung-Bo Huh ${ }^{1, *}$ \\ 1 Department of Prosthodontics, Dental Research Institute, Dental and Life Science Institute, \\ BK21 PLUS Project, School of Dentistry, Pusan National University, Yangsan 50612, Korea; \\ 0228dmqls@hanmail.net (E.-B.B.); tarov0414@daum.net (J.-J.A.); h.02@hanmail.net (H.-Y.B.) \\ 2 Department of Oral Physiology, Dental Research Institute, Dental and Life Science Institute, \\ School of Dentistry, Pusan National University, Yangsan 50612, Korea; ya120010@naver.com \\ * Correspondence: hjoonkim@pusan.ac.kr (H.-J.K.); neoplasia96@hanmail.net (J.-B.H.); \\ Tel.: +82-10-6326-4189 (H.-J.K.); Tel.: +82-10-8007-9099 (J.-B.H.); \\ Fax: +82-55-510-8208 (H.-J.K.); Fax: +82-55-360-5134 (J.-B.H.) \\ + These authors contributed equally to this work.
}

Received: 26 September 2019; Accepted: 16 October 2019; Published: 18 October 2019

\begin{abstract}
The present study aimed to compare the bone-regeneration capacity of porcine-derived xenografts to bovine-derived xenografts in the rat calvarial defect model. The observation of surface morphology and in vitro cell studies were conducted prior to the animal study. Defects with a diameter of $8 \mathrm{~mm}$ were created in calvaria of 20 rats. The rats were randomly treated with porcine-derived (Bone-XP group) or bovine-derived xenografts (Bio-Oss group) and sacrificed at 4 and 8 weeks after surgery. The new bone regeneration was evaluated by micro-computed tomography $(\mu \mathrm{CT})$ and histomorphometric analyses. In the cell study, the extracts of Bone-XP and Bio-Oss showed a positive effect on the regulation of osteogenic differentiation of human mesenchymal stem cells (hMSCs) without cytotoxicity. The new bone volume of Bone-XP $(17.52 \pm 3.78 \%$ at 4 weeks and $32.09 \pm 3.51 \%$ at 8 weeks) was similar to that of Bio-Oss $(11.6 \pm 3.88 \%$ at 4 weeks and $25.89 \pm 7.43 \%$ at 8 weeks $)$ $(p>0.05)$. In the results of new bone area, there was no significant difference between Bone-XP $(9.08 \pm 5.47 \%$ at 4 weeks and $25.22 \pm 13.56 \%$ at 8 weeks) and Bio-Oss groups $(5.83 \pm 2.56 \%$ at 4 weeks and $21.68 \pm 11.11 \%$ at 8 weeks) $(p>0.05)$. It can be concluded that the porcine-derived bone substitute may offer a favorable cell response and bone regeneration similar to those of commercial bovine bone mineral.
\end{abstract}

Keywords: bone regeneration; bone substitute; xenograft; porcine bone

\section{Introduction}

An insufficient alveolar bone volume can produce the problems of implant insertion and prognosis, therefore, bone graft materials have been commonly used to reconstruct the osseous defects in the implant and periodontic surgeries. Bone grafting not only fills the boneless space but also provides structural stability and facilitates bone tissue growth [1]. For successful bone regeneration, numerous bone substitutes have been developed and introduced using autogenous bone, allografts, synthetic bone, and xenografts [2,3].

Among them, autogenous bone has been considered a gold standard for bone regeneration from biological and histological vantage points [4]. Nonetheless, autografts have not frequently been applied in clinical application due to concerns about additional injury, donor site limitations, and morbidity 
from the bone harvest $[5,6]$. On the contrary, xenogeneic bone substitutes derived from bones of other species also a have sufficient osteoconductivity and biocompatibility and have generally been used in the dental field [7]. Besides, unlike autogenous bone, xenografts circumvent a second operative site and have no limit in terms of the available bone amount $[1,8]$.

Currently, the deproteinized cancellous bovine bone matrix (DBBM) is mainly transplanted in alveolar bone defects and in sinus floor augmentation $[9,10]$. The most well-known DBBM in dentistry is Bio-Oss ${ }^{\circledR}$ with successful preclinical and clinical results, which has similar porous structure to human bone and shows high biocompatibility with oral hard tissues, and also meets the criteria of bone conductivity [1,11-13]. Such a graft consists of hydroxyapatite prepared by alkaline and heat treatment $\left(300^{\circ} \mathrm{C}\right)$ for eliminating the organics of the bone. However, in using the bovine-derived bone substitute, the fear of bovine spongiform encephalopathy (BSE) transmission is still potentially inherent [14]. BSE is a kind of transmissible spongiform encephalopathies (TSE), a fatal neurodegenerative disorder that can be transmitted to humans [15].

Porcine bone also shares a similar physiological, anatomic, and genetic makeup to human [16-18]. Hence the porcine-derived xenografts with relatively low zoonosis risk have been recently developed and made commercially available as an alternative to bovine-derived xenografts $[16,19,20]$. Porcine xenogeneic bone substitute has crystal structures similar to the human-derived bones like bovine bone $[18,21]$. Moreover, the stiffness and $\mathrm{Ca} / \mathrm{P}$ ratio of porcine xenograft are closer to human trabecular bone than bovine bone [22]. Despite the porcine-derived xenografts having crystalline structures resembling human osseous tissue seem to be a profitable bone graft, the researches and data on porcine-derived xenografts still lack compared to bovine-derived grafts.

In the present study, we expected that the porcine-derived xenograft (Bone- $X \mathrm{P}^{\circledR}$ ) recently introduced in the dental field may serve either non-inferior or superior effects on bone regeneration compare to the well-known commercially available bovine-derived bone substitute (Bio-Oss ${ }^{\circledR}$ ). Thus, this study was undertaken to compare the bone regeneration capacity of porcine-derived xenografts to bovine-derived xenografts in the rat calvarial defect model.

\section{Materials and Methods}

\subsection{Experimental Xenogenetic Bone Substitues}

Two kinds of commercially available xenogeneic bone substitutes derived from different species (porcine and bovine) were used in this study. For porcine-derived xenograft (Bone-XP group), Bone- $\mathrm{XP}^{\circledR}$ (particle size of $0.2 \mathrm{~mm}-1.0 \mathrm{~mm}$ ) was purchased from Medpark (Busan, Korea). Bovine bone graft material (Bio-Oss group), Bio-Oss ${ }^{\circledR}$ (particle size of $0.25-1.0 \mathrm{~mm}$ ), was purchased from Geistlich Biomaterials (Wolhusen, Switzerland).

\subsection{In Vitro Study}

\subsubsection{Scanning Electron Microscopy (SEM)}

To compare the surface morphologies of porcine and bovine xenogeneic bone substitute, scanning electron microscopy (SEM) observation was conducted. After coating the Bio-Oss and Bone-XP with Au using a sputter coater (SCD 005, BAL-TEC, Balzers, Liechtenstein), the SEM (Hitachi S3500N, Hitachi, Tokyo, Japan) was operated at $15 \mathrm{kV}$.

\subsubsection{Preparation of Extracts}

We mixed $1 \mathrm{~g}$ of each xenogeneic bone substitute (Bio-Oss and Bone-XP) with $10 \mathrm{~mL}$ of alpha-modification of Eagle's medium ( $\alpha$-MEM; Welgene, Deagu, Korea) and stored at $37^{\circ} \mathrm{C}$ and $5 \%$ $\mathrm{CO}_{2}$ for 1 day. Each suspension was centrifuged once, for $5 \mathrm{~min}$ at $1200 \times g$. These suspensions were filtered through the membrane (pore size: $0.2 \mu \mathrm{m}$ ) and stored $4{ }^{\circ} \mathrm{C}$ before use. The concentration of extract solutions in culture media ranging $20 \%$ was treated. 


\subsubsection{Culture of Human Bone Marrow Mesenchymal Stem Cells (hMSCs)}

Human mesenchymal stem cells (hMSCs) (LONZA, Walkersville, MD, USA) were used for this in vitro cell study. hMSCs culture medium consisted of alpha-modification of Eagle's medium ( $\alpha$-MEM; Welgene Inc., Deagu, Korea) supplemented with $10 \%$ fetal bovine serum (FBS; Gibco BRL, Carlsbad, CA, USA), $100 \mathrm{U} / \mathrm{mL}$ penicillin and $100 \mu \mathrm{g} / \mathrm{mL}$ streptomycin (Gibco BRL), at $37^{\circ} \mathrm{C}, 5 \% \mathrm{CO}_{2}$. The cultured medium was changed regularly every three days. The cells were detached with $0.25 \%$ trypsin/1 mM EDTA (Gibco BRL) and passaged after reaching 80\%-90\% confluence. hMSCs between Passages 4 and 5 were used for all the experiments.

\subsubsection{Differentiation toward Osteoblasts}

For osteogenic differentiation, hMSC s were seeded into a 48 -well plate $\left(3 \times 10^{4}\right.$ cells $\left./ \mathrm{mL}\right)$ in $\alpha$-MEM and incubated at $37^{\circ} \mathrm{C}$ and $5 \% \mathrm{CO}_{2}$ for $24 \mathrm{~h}$. The media was replaced to osteogenic differentiation media, i.e., $10 \% \alpha$-MEM supplemented with $50 \mu \mathrm{g} / \mathrm{mL}$ ascorbic acid-2-phosphate (Sigma-Aldrich, Milan, Italy) and $10 \mathrm{mM} \beta$-glycerophosphate (Sigma-Aldrich), which function as a positive control. Media was changed every two days.

\subsubsection{Cell Viability and Proliferation Assay}

The cell viability and proliferation were assessed using the CCK-8 assay kit (Dojindo, Rockville, MD, USA) at 0, 1, 2, and 3 days. hMSCs were seeded into 48-well plates (Nunc, Roskilde, Denmark) at a density of $1 \times 10^{4}$ cells $/ \mathrm{mL}$. Each plate was pre-incubated in a humidified incubator with $5 \% \mathrm{CO}_{2}$ at $37^{\circ} \mathrm{C}$, and $20 \mu \mathrm{L}$ of the CCK-8 solution was added to each well and then incubated for $2 \mathrm{~h}$. $100 \mu \mathrm{L} /$ well aliquots were transferred to a 96-well plate (Nunc) and absorbance was measured at $450 \mathrm{~nm}$ using an Opsys MR micro-plate reader (DYNEX Technologies Inc., Denkendorf, Germany). The cell viability was determined in $24 \mathrm{~h}$ absorbance data. The cell proliferation rate was assessed in optical density (OD) units.

\subsubsection{Alkaline Phosphatase (ALP) Activity Assay}

To evaluate the osteogenic differentiation, we used the Leukocyte Alkaline Phosphatase Kit (Sigma-Aldrich) according to the manufacturer's protocol. hMSCs were plated into 48-well plates (Nunc) at a density of $3 \times 10^{4}$ cells $/ \mathrm{mL}$ and cultured for 3 and 8 days in the osteogenic media. Quantification of the staining images were done using ImageJ software program (U.S. National Institutes of Health, Bethesda, MD, USA).

\subsubsection{Real-Time Polymerase Chain Reaction (PCR) Analysis}

The real-time polymerase chain reaction (PCR) analysis was performed to examine the gene level of osteogenic differentiation markers. hMSCs were seeded into a 6 -well plate $\left(2 \times 10^{4}\right.$ cells $\left./ \mathrm{mL}\right)$. The cells cultured under the basal $\alpha$-MEM, and the osteogenic $\alpha$-MEM media were used as controls. Five days after the induction of osteogenesis, total RNA was extracted from different treated cells by using TRIzol (Life Technologies, Grand Island, NY, USA), and the total RNA concentration was measured by using a NanoDrop ND-1000 spectrophotometer (Technologies Inc., Wilmington, DE, USA). Complementary DNA (cDNA) was synthesized from $1.5 \mu \mathrm{g}$ of the RNA. Amplification was done by using SYBR Green Master Mix reagents (Kapa Biosystems, Woburn, MA, USA) and an ABI 7500 instrument (Applied Biosystems, Carlsbad, CA, USA) according to the manufacturer's protocols. The relative gene expressions ( $A L P$, Osteopontin $(O P N)$, and Runt-related transcription factor 2 (RUNX2)) were calculated using the relative 2- $\Delta \Delta \mathrm{Ct}$ method. The control gene, Actin, was used to normalize the target genes. All reactions were performed in three samples. The primers were synthesized and provided by Bionics (Daejeon, Korea) (Table 1). 
Table 1. Primer sequences used for real-time polymerase chain reaction (PCR) analysis.

\begin{tabular}{cc}
\hline Target Genes & Sequences \\
\hline \multirow{2}{*}{ ALP } & F: 5'-ATTTCTCTTGGGCAGGCAGAGAGT-3' \\
& R: 5'-ATCCAGAATGTTCCACGGAGGCTT-3' \\
OPN & F: 5'-AGACACATATGATGGCCGAGG-3' \\
& R: 5'-GGCCTTGTATGCACCATTCAA-3' \\
Runx2 & F: 5'-CTCTACTATGGCACTTCGTCAGG-3' \\
& R: 5'-GCTTCCATCAGCGTCAACAC-3' \\
Actin & F: 5'-ACTCTTCCAGCCTTCCTTCC-3' \\
& R: 5'-TGTTGGCGTACAGGTCTTTG-3' \\
\hline
\end{tabular}

\subsection{In Vivo Animal Study}

\subsubsection{Experimental Animal and Operative Procedures}

Twenty Sprague-Dawley rats (male, 13-week-old, Koatech, Pyeongtaek, Korea) were used in this animal experiment. The individually caged rats were fed with rodent pellets and water and adapted to the laboratory for a week prior to surgery. The room conditions were kept constant at a temperature of $25 \pm 1{ }^{\circ} \mathrm{C}$ and at a humidity of $55 \pm 7 \%$. All the animal care and surgical procedures were done at the Laboratory Animal Resource Center of Pusan National University and were approved by the Institutional Animal Care and Use Committee of Pusan National University (PNU-2018-2101). During the surgical procedure, the rats were anesthetized using intramuscular injection of a combination of xylazine (Rompun, Bayer Korea, Seoul, Korea) and tiletamine zolazepam (Zoletil50, Virbac Korea, Seoul, Korea) for general anesthesia. The surgical sites of rats were shaved and then disinfected with povidone-iodine (Betadine, Korea Pharma, Seoul, Korea). The local anesthesia was performed using $2 \%$ lidocaine (Huons, Soengnam, Korea). After making a sagittal incision across the center of the skull using surgical scalpel blade (No. 15, Swann-Morton Ltd., Sheffield, UK), the cranium was exposed by raising the full thickness flap. Using a saline-cooled trephine bur (Osung, Kimpo, Korea), a critical-sized osseous defect ( $8 \mathrm{~mm}$ in diameter) was made in the center of the skull (Figure 1a). The quantified xenogeneic bone grafts $(0.03 \pm 0.002 \mathrm{~g})$ were randomly implanted in each defect (Figure $1 \mathrm{~b})$. The defect was covered with a resorbable collagen membrane $(10 \times 10 \mathrm{~mm}$, Cola-D, Medpark, Seoul, Korea) (Figure 1c). Skin and periosteum were sutured using 4-0 Vicryl suture (Ethicon, Livingston, UK). At 4 and 8 weeks after surgery, the experimental rats were sacrificed by $\mathrm{CO}_{2}$ inhalation. The tissue samples were carefully harvested and immersed in 10\% neutral buffered formalin (Sigma-Aldrich) for 2 weeks.
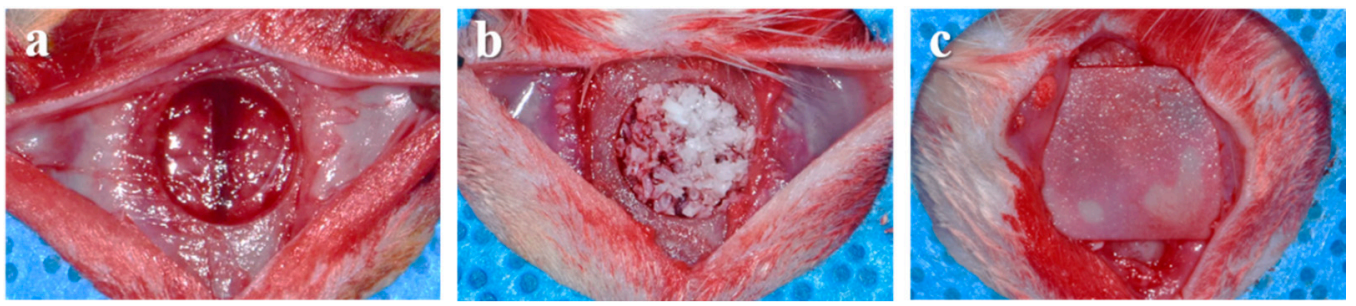

Figure 1. Operative procedures using rat calvarial defect model. (a) Created calvarial defect, (b) insertion of bone grafts, (c) placement of collagen membrane.

\subsubsection{Micro-Computed Tomography $(\mu \mathrm{CT})$ Analysis}

All the harvested samples were scanned using $\mu \mathrm{CT}$ (SMX-90CT, Shimadzu, Kyoto, Japan) at $90 \mathrm{kV}$, intensity of $109 \mu \mathrm{A}$ for measuring the percentage of new bone volume. The new bone volume was calculated using a customized program corded by cording software (MATLAB 2018b, MathWorks, Natick, MA, USA). The area of interest (AOI) was set as the same for all the specimens (diameter of 
$8 \mathrm{~mm}$, height of $1.5 \mathrm{~mm}$ ) (Figure 2). The images were divided into soft tissue, bone graft material and new bone and were classified by threshold values.

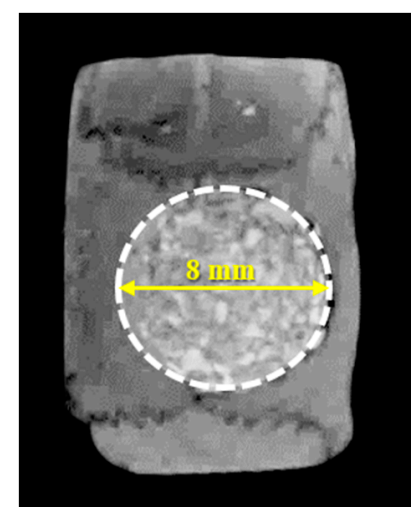

Figure 2. Area of interest (AOI) for volumetric analysis.

\subsubsection{Histological and Histomorphometric Analysis}

To prepare the decalcified histological sections, fixed-tissue specimens were soaked in $2.5 \%$ sodium hypochlorite/17\% Ethylenediaminetetraacetic acid (EDTA) solution, and the solution was replaced daily for 2 weeks. Afterwards, specimens were dehydrated in a graded ethanol series and xylene and were embedded in paraffin. The paraffin blocks were cut into 3-4 $\mu \mathrm{m}$ thickness using a microtome (Microm HM 325, Waltham, MA, USA) and then attached to poly-L-lysine-coated slides. The tissue specimens were stained with hematoxylin-eosin (H\&E) and Masson's trichrome (MT) staining solutions and photographed by optical microscope (Olympus BX, Tokyo, Japan) attached CCD camera (Polaroid DMC2 digital Microscope Camera, Polaroid, Cambridge, MA, USA). The newly formed bone area at the defect sites were consistently measured using a i-solution (IMT, Daejeon, Korea) by a single investigator (Figure 3).

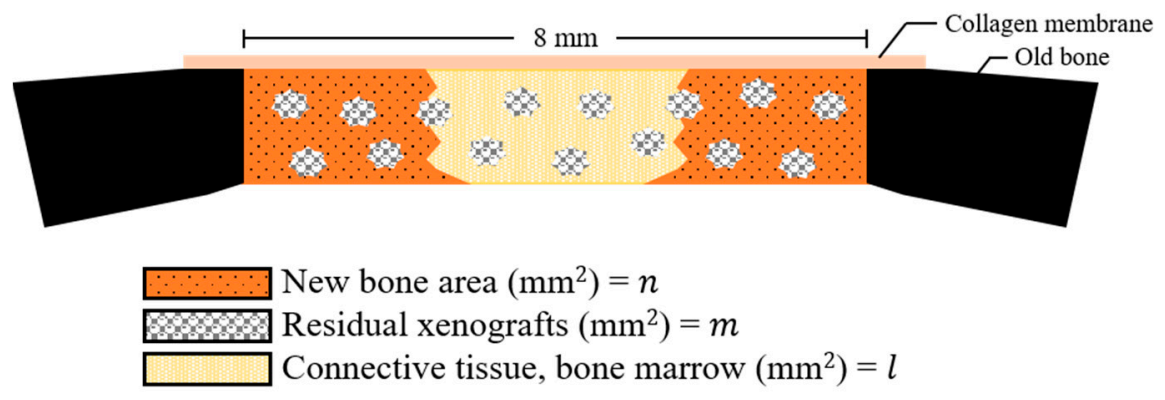

$$
\text { New bone area percentage }(\%)=\frac{n}{n+m+l} \times 100
$$

Figure 3. Schematic diagram of histometric analysis.

\subsection{Statistical Analysis}

All the statistical analyses were performed using SPSS statistical analysis software (ver. 24.0, IBM, Armonk, NY, USA) with a confidence level of $95 \%(p<0.05)$. The in vitro and in vivo results were analyzed by using the independent student's $t$-test to determine the significance of differences between groups. 


\section{Results}

\subsection{In Vitro Findings}

\subsubsection{Observations of Surface Morphology}

To investigate the surface morphologies of bone grafts, the SEM images were captured at magnification of $\times 60, \times 500$, and $\times 2000$ (Figure 4). The xenografts of both groups showed similar particle size (Figure $4 \mathrm{a}, \mathrm{b}$ ) and macro-porous structure (Figure $4 \mathrm{c}-\mathrm{f}$ ) exhibiting the rough surfaces.
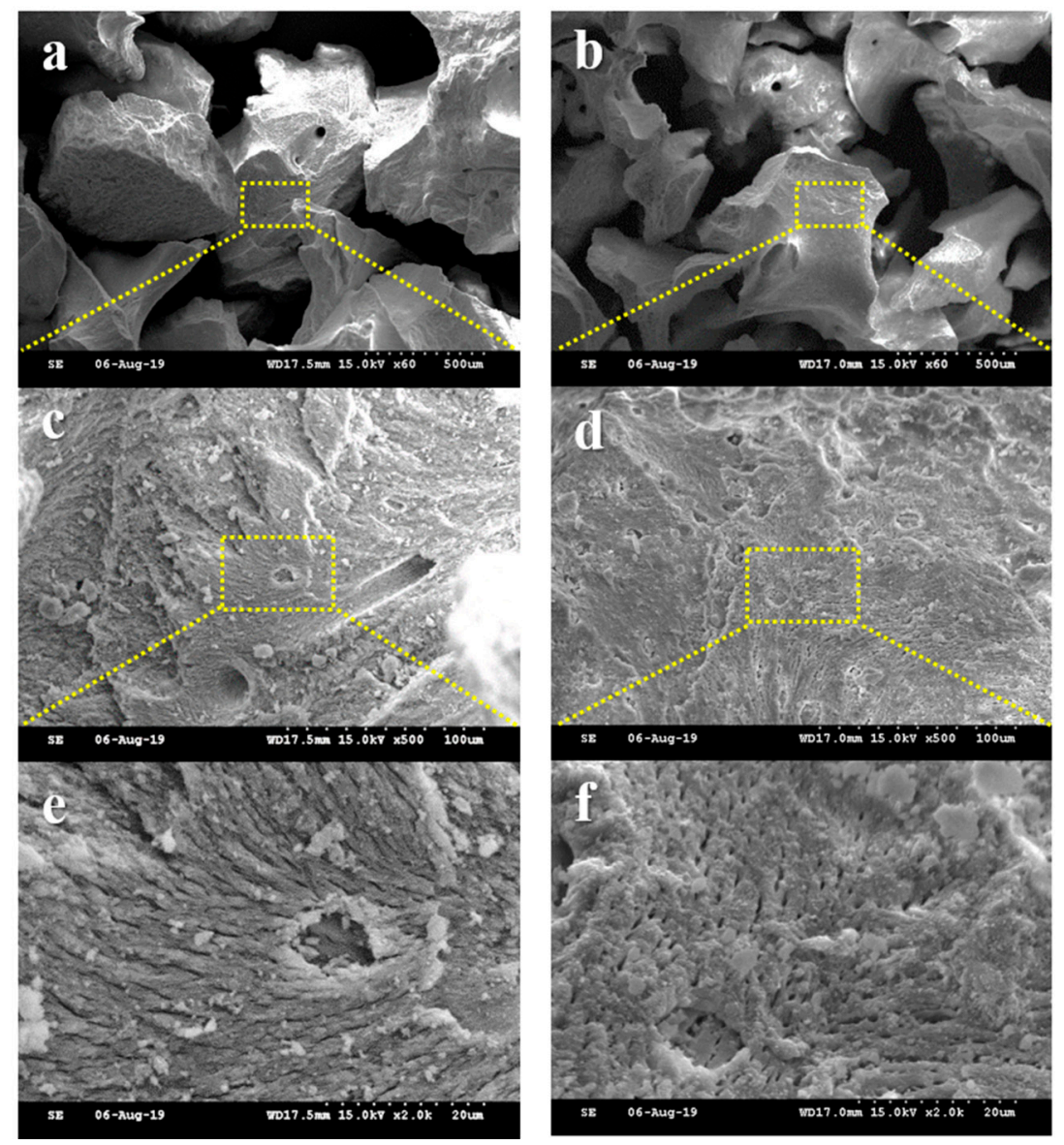

Figure 4. Comparative scanning electron microscope (SEM) images of each group. (a,c,e) Bio-Oss and $(\mathbf{b}, \mathbf{d}, \mathbf{f})$ Bone-XP groups. [Original magnification: $\times 60(\mathbf{a}, \mathbf{b}), \times 500(\mathbf{c}, \mathbf{d}), \times 2000(\mathbf{e}, \mathbf{f})]$.

\subsubsection{Cell Viability and Proliferation}

The viability and proliferation of hMSCs on the two different extracts were analyzed using the CCK-8 assay, 0, 1, 2, and 3 days after cell seeding. At each time point, cell numbers were calculated following the normalization of the absorbance units to that obtained for the cells cultured on the Control group (Figure 5). At 1 day, the number of viable cells was similar for the extracts of Bio-Oss group and Bone-XP group and no significant differences were observed (Figure 5a). After 1, 2, and 3 days of culture, the cell proliferation of hMSCs on the two extracts was no different to that of the Control group (Figure $5 b$ ). These results indicate that the hMSCs cultured on two extractsf had no affect toxicity, and the proliferation rate was quite modest. 
a

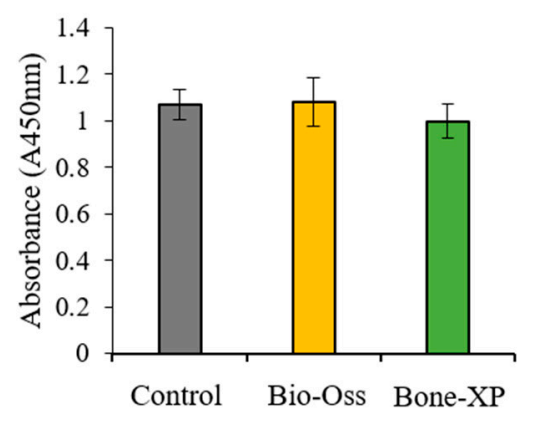

b

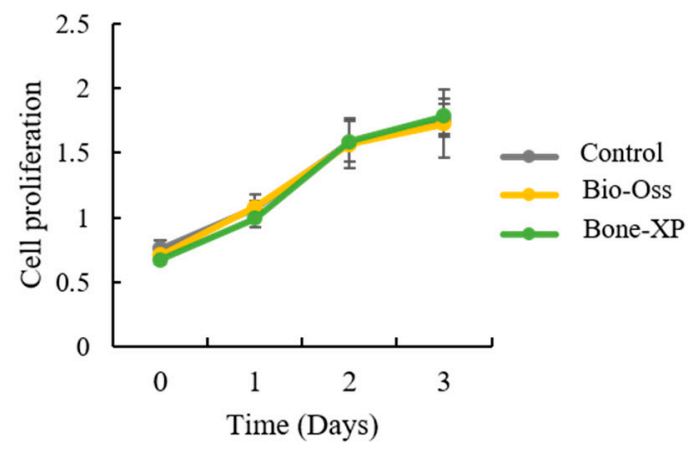

Figure 5. (a) Cell viability and (b) proliferation of extracts on human mesenchymal stem cells (hMSCs).

\subsubsection{Alkaline Phosphatase (ALP) Staining}

The alkaline phosphatase staining was conducted to analyze the effect of Control untreated hMSCs and those treated either with Bio-Oss group or Bone-XP group extracts after incubation for 3 and 8 days (Figure 6). On day 3, ALP staining slightly increased in the cells cultured on both the Bio-Oss group and Bone-XP group compared to the Control group. In addition, there was no obvious staining difference between Bio-Oss group and Bone-XP group-treated hMSCs. On day 8, both Bio-Oss group and Bone-XP group treated hMSCs, which were not substantially different from each other, showed higher staining than the Control, untreated cells. These data suggest that the extracts of Bio-Oss and Bone-XP had a positive effect on the regulation of osteogenic differentiation of hMSCs.

$\mathbf{a}$

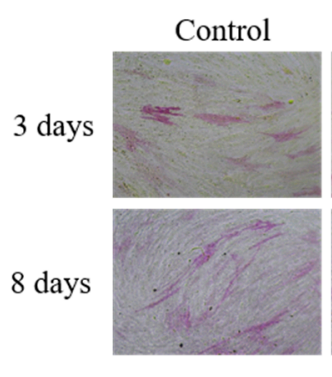

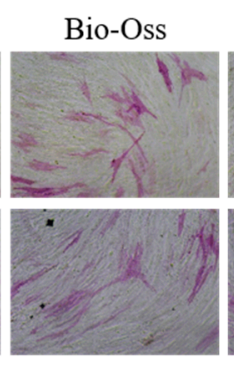

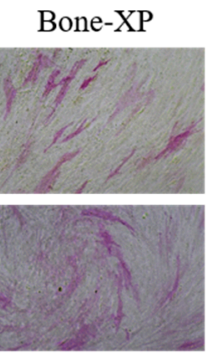

b

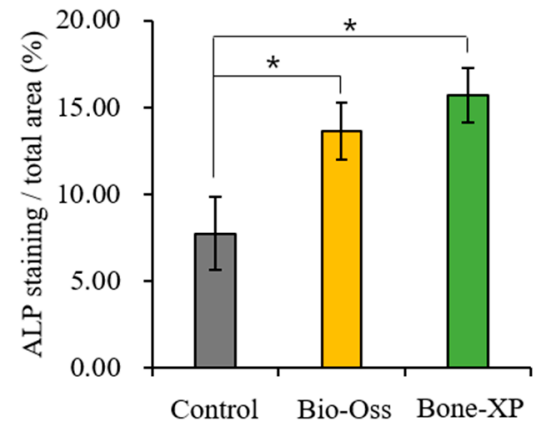

Figure 6. Cell osteogenic differentiation assay. (a) Alkaline phosphatase (ALP) staining and (b) the quantitative analysis. The symbol * indicates statistical significance compare to control $\left({ }^{*} p<0.05\right)$.

\subsubsection{Analysis of Real-time Polymerase Chain Reaction (PCR)}

It is important to note that $A L P$ and RUNX2 were an early marker of osteoblastic lineage, and to evaluate the effects of Bio-Oss and Bone-XP extracts on osteoblast differentiation. The levels of osteogenesis-related genes were examined by real-time PCR (Figure 7). hMSCs were cultured in medium supplemented with osteogenic factors and $20 \%$ extracts for 5 days. Compared with control, untreated hMSCs, the up-regulated genes by Bio-Oss and Bone-XP extracts induced the factors involved in osteoblast differentiation and matrix mineralization, $A L P$ and OPN (Figure 7a,b) and key osteogenic transcriptional factor; RUNX2 (Figure 7c). Additionally, there was no statistically significant difference between Bio-Oss and Bone-XP-treated hMSCs (Figure 7a,b). 

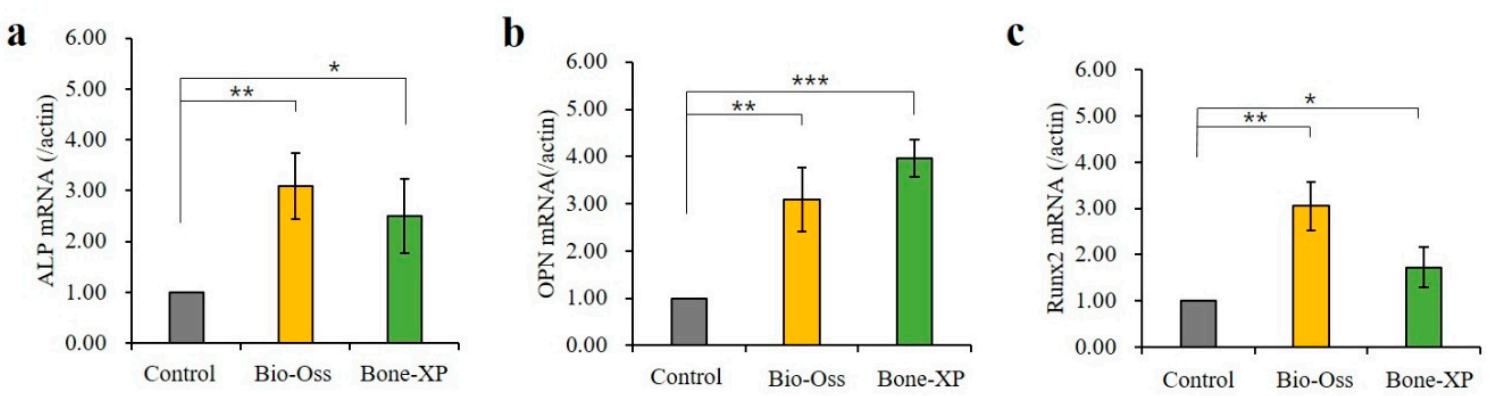

Figure 7. Real-time polymerase chain reaction (PCR) analysis of hMSCs on extracts. (a) ALP, (b) OPN, and (c) RUNX2 were selected as the osteogenic differentiation related genes. The symbol * indicates statistical significance compare to control group $\left({ }^{*} p<0.05,{ }^{* *} p<0.01,{ }^{* * *} p<0.001\right)$.

\subsection{In Vivo Findings}

\subsubsection{Clinical Findings}

All the rats survived during the operative procedures and healing periods. In all the surgical sites, any side effects such as inflammation, swelling, or exposure of the specimens were not observed.

\subsubsection{Volumetric Findings}

On $\mu \mathrm{CT}$ images, bone grafts were well-positioned in the AOI without scattering of particles (Figure 8a-d). Within the AOI, the similar amount of new bone areas classified by threshold were observed in both experimental groups at 4 weeks and 8 weeks, respectively (Figure 8i-1). At 4 weeks, the new bone volumes (\%) of Bio-Oss and Bone-XP groups were $11.6 \pm 3.88 \%$ and $17.52 \pm 3.78 \%$, respectively (Table 2 and Figure 9). At 8 weeks, new bone volumes of Bio-Oss group and Bone-XP group were $25.89 \pm 7.43 \%$ and $32.09 \pm 3.51 \%$, respectively. There was no significant difference in new bone volume between groups at both 4 and 8 weeks $(p>0.05)$.
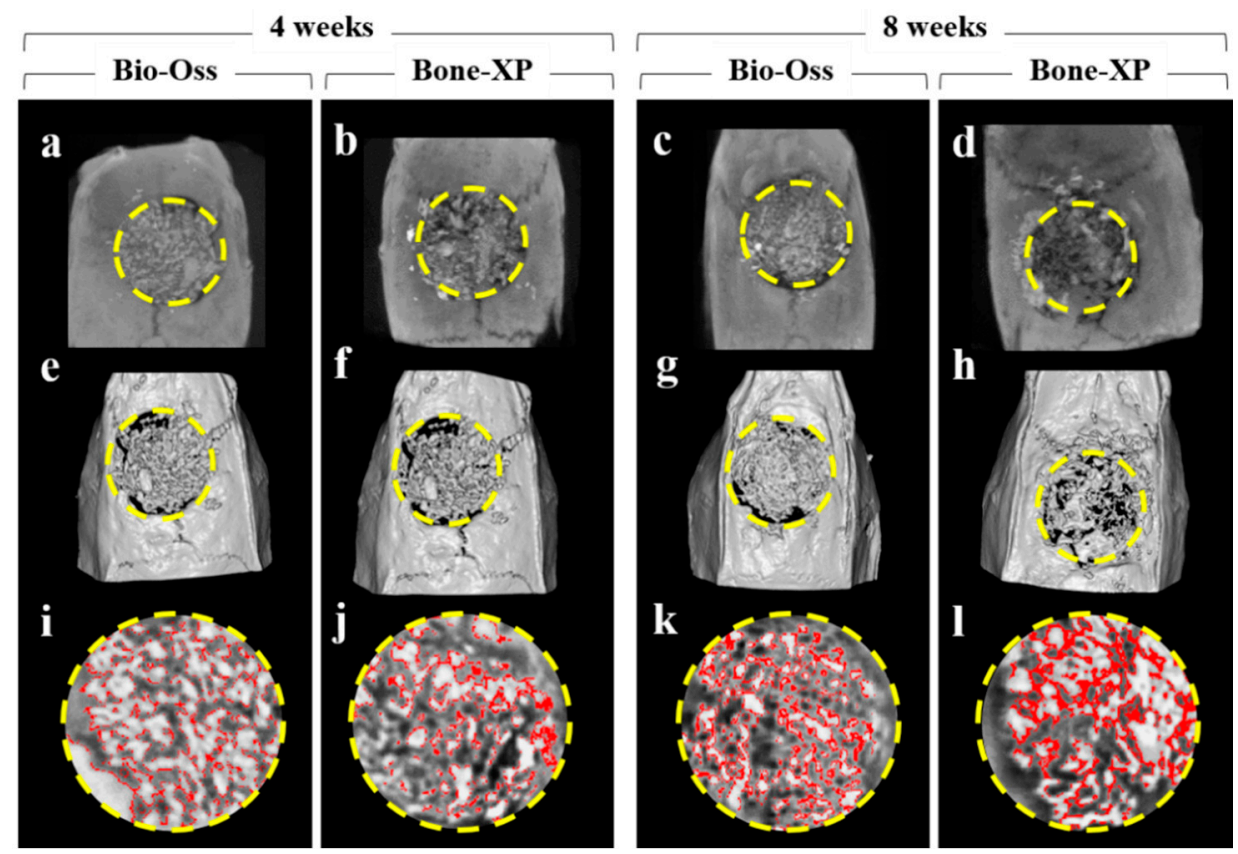

Figure 8. Micro-computed tomography $(\mu \mathrm{CT})$ analysis images. (a-d) $\mu \mathrm{CT}$ images. (e-h) $3 \mathrm{D}$ reconstructed $\mu \mathrm{CT}$ images. (i-1) Classified new bone in area of interest (AOI). Yellow circle: AOI, Red colored area: newly formed bone. 
Table 2. New bone volume within area of interest (AOI). $(n=5)$.

\begin{tabular}{|c|c|c|c|c|c|}
\hline & & Groups & Mean & SD & $p$-Value \\
\hline \multirow{2}{*}{ New bone volume (\%) } & 4 weeks & $\begin{array}{c}\text { Bio-Oss } \\
\text { Bone-XP }\end{array}$ & $\begin{array}{c}11.6 \\
17.52\end{array}$ & $\begin{array}{l}3.88 \\
3.78\end{array}$ & 0.092 \\
\hline & 8 weeks & $\begin{array}{c}\text { Bio-Oss } \\
\text { Bone-XP }\end{array}$ & $\begin{array}{l}25.89 \\
32.09\end{array}$ & $\begin{array}{l}7.43 \\
3.51\end{array}$ & 0.38 \\
\hline
\end{tabular}

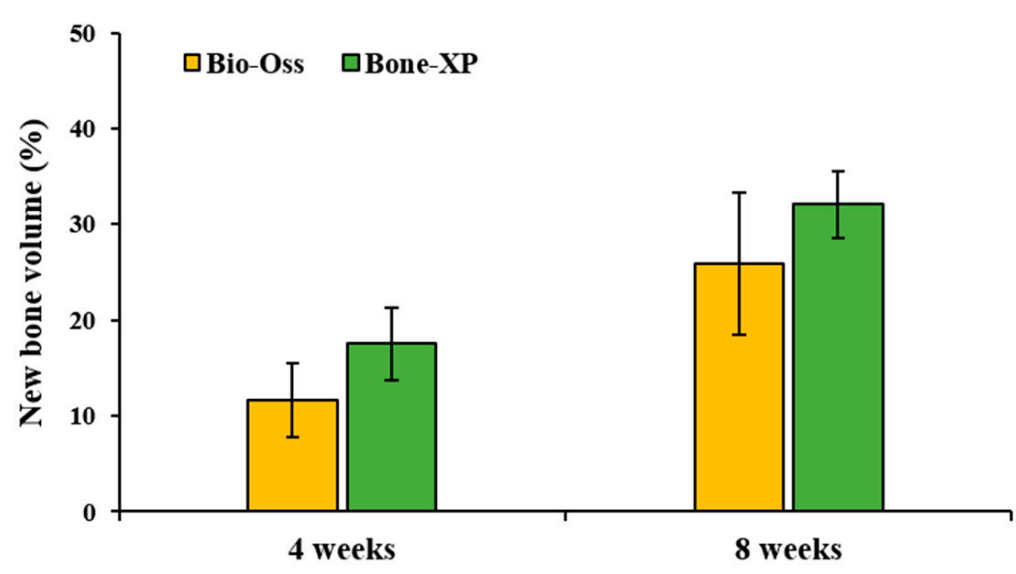

Figure 9. New bone volume percentages within area of interest (AOI).

\subsubsection{Histological and Histomorphometric Findings}

In all the histologic sections, the implanted bone-graft materials were holding a stable position within the defective site and showed good space-maintenance for bone reconstruction (Figures 10 and 11). At all the time point of 4 and 8 weeks, there were no remarkable inflammatory reactions such as presence of inflammatory cells or hematoma forms, and a number of active osteoblasts' lines could be easily found surrounding the newly formed bone (Figures 10i-1 and 11i-1). In addition, connective tissues and bone marrow were observed around the residual bone graft materials. At 4 weeks after surgery, the new bones were minimally regenerated from the defect margin in both groups (Figure 4). The bone rebuilding was time-dependent, the mineralization and amount of new bone were increased at 8 weeks compared to those of 4 weeks in both groups (Figure 11).

The histomeric results of new bone area at 4 and 8 weeks after surgery are shown in Table 3 and Figure 12. At 4 weeks post-surgery, the mean \pm standard deviation (SD) of new bone areas (\%) in Bio-Oss and Bone XP groups were $5.83 \pm 2.56 \%, 9.08 \pm 5.47 \%$, respectively. At 8 weeks, the new bone areas of Bio-Oss and Bone XP groups were $21.68 \pm 11.11 \%$ and $25.22 \pm 13.56 \%$, respectively. There was no significant difference in new bone volume between groups at both 4 and 8 weeks $(p>0.05)$. 


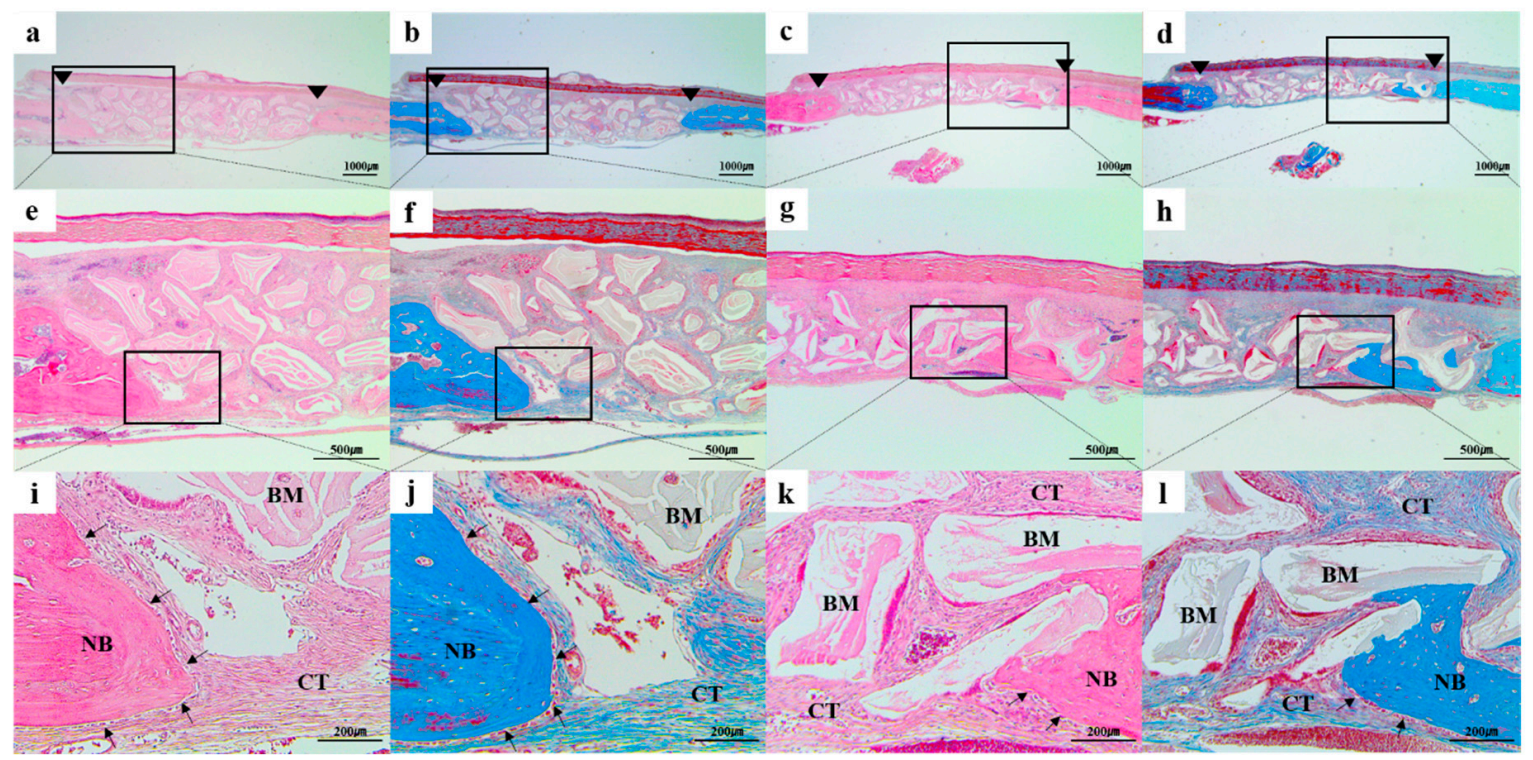

Figure 10. Histologic sections of $(\mathbf{a}, \mathbf{b}, \mathbf{e}, \mathbf{f}, \mathbf{i}, \mathbf{j})$ Bio-Oss and $(\mathbf{c}, \mathbf{d}, \mathbf{g}, \mathbf{h}, \mathbf{k}, \mathbf{l})$ Bone-XP groups at 4 weeks post-surgery. (a,c,e,g,i, $\mathbf{i}$ ) haematoxylin and eosin (H\&E) stained slides; $(\mathbf{b}, \mathbf{d}, \mathbf{f}, \mathbf{h}, \mathbf{j}, \mathbf{l})$ Masson's trichrome (MT) stained slides; Arrowhead: original defect edge; Arrow: lines of osteoblasts NB: newly generated bone; CT: connective tissue; BM: residual bone grafts. [Original magnification: $(\mathbf{a}-\mathbf{d}) \times 12.5,(\mathbf{e}-\mathbf{h}) \times 40$, $(\mathbf{i}-1) \times 100]$.

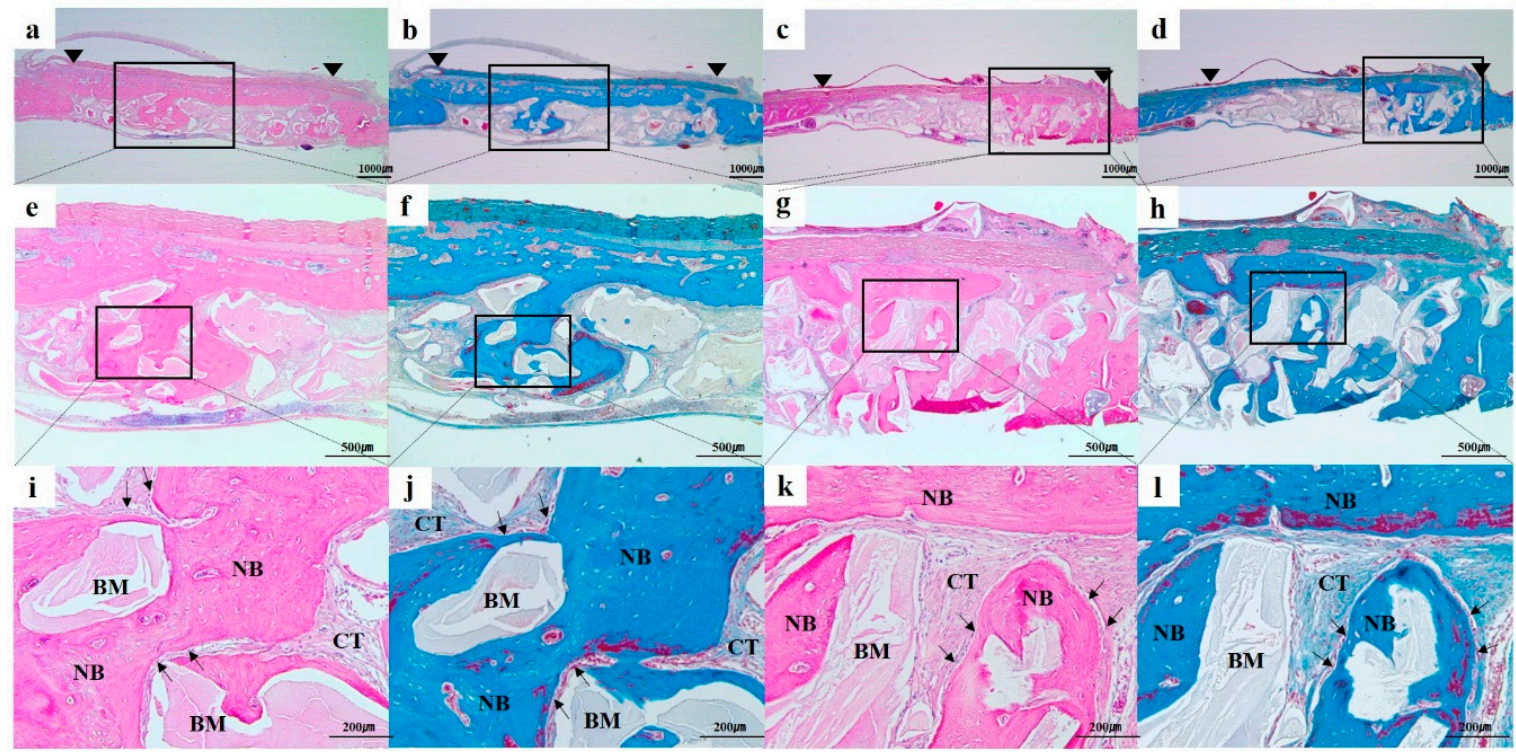

Figure 11. Histologic sections of $(\mathbf{a}, \mathbf{b}, \mathbf{e}, \mathbf{f}, \mathbf{i}, \mathbf{j})$ Bio-Oss and $(\mathbf{c}, \mathbf{d}, \mathbf{g}, \mathbf{h}, \mathbf{k}, \mathbf{l})$ Bone-XP groups at 8 weeks post-surgery. (a,c,e,g,i, $\mathbf{k})$ haematoxylin and eosin (H\&E) stained slides; (b,d,f,h, $\mathbf{j}, \mathbf{l})$ Masson's trichrome (MT) stained slides; Arrowhead: original defect edge; Arrow: lines of osteoblasts NB: newly generated bone; CT: connective tissue; BM: residual bone grafts. [Original magnification: $(\mathbf{a}-\mathbf{d}) \times 12.5,(\mathbf{e}-\mathbf{h}) \times 40$, $(\mathbf{i}-1) \times 100]$. 
Table 3. New bone area within area of interest (AOI). $(n=5)$.

\begin{tabular}{|c|c|c|c|c|c|}
\hline & & Groups & Mean & SD & $p$-Value \\
\hline \multirow{4}{*}{ New bone area $(\%)$} & 4 weeks & Bio-Oss & 5.83 & 2.56 & \multirow{2}{*}{0.139} \\
\hline & 4 weeks & Bone-XP & 9.08 & 5.47 & \\
\hline & \multirow{2}{*}{8 weeks } & Bio-Oss & 21.68 & 11.11 & \multirow{2}{*}{0.273} \\
\hline & & Bone-XP & 25.22 & 13.56 & \\
\hline
\end{tabular}

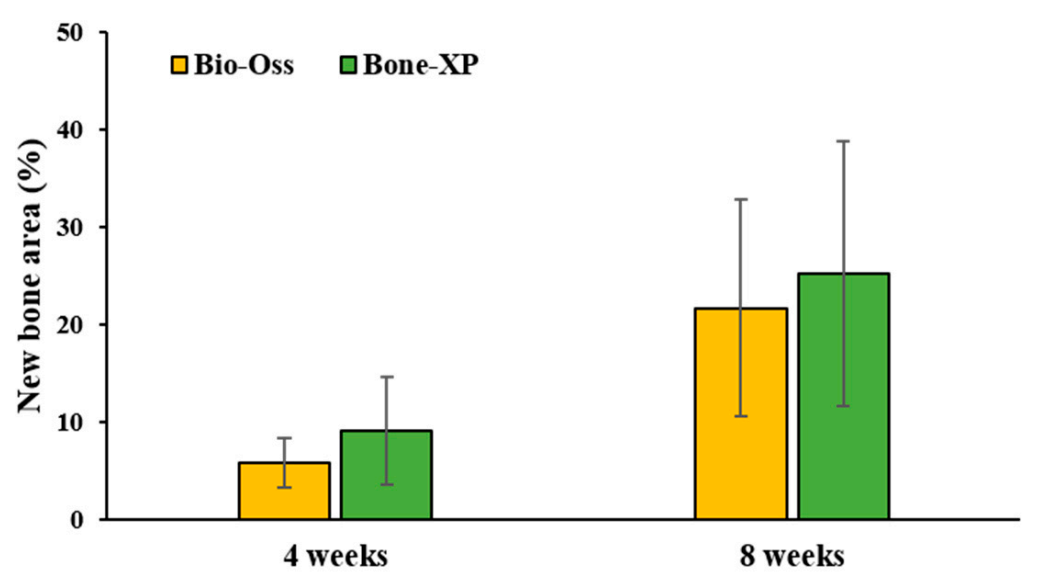

Figure 12. New bone area percentages within area of interest (AOI).

\section{Discussion}

Porcine-derived xenografts are a biocompatible material and have similar structures to that of human bone [23]. Bone-XP ${ }^{\circledR}$ used in our study is a heat-treated mineralized porcine bone, commercially available in dentistry. To remove the residual organic components, Bone- $\mathrm{XP}{ }^{\circledR}$ was produced by thermal-treatment at high temperature. The high-temperature thermal treatment gives a higher crystalline structure and longer hydroxyapatite crystal [24,25]. While the heat-treatment may influence the $\mathrm{Ca} / \mathrm{P}$ ratio, it is reported that the $\mathrm{Ca} / \mathrm{P}$ ratio of Bone- $\mathrm{XP}(1.65-1.66)$ is closer to the $\mathrm{Ca} / \mathrm{P}$ ratio of human bone (1.68-1.71) than that of bovine bone (1.92) [22]. An et al. [26] conducted animal experiments using the porcine-derived xenogeneic bone substitutes and reported the uniform new bone formation in rabbit tibia at 16 weeks post-surgery. They also conducted the multicenter clinical trial in orthopedics and proved the safety, stability, and appropriate absorption rate of porcine bone in the ilium. In addition, in the case report for alveolar ridge preservation using porcine bone mineral, the smooth new bone formation could be observed around the grafted xenografts without any adverse events such as inflammatory reaction or fibrous film formation [27]. The measured new bone rate (37.4\%) was not inferior to the similar previous studies on ridge preservation using allogeneic bone and DBBM [27-29]. Even though there are lots of advantageous points of thermal-treated mineralized porcine xenografts, since most of the previous works on porcine bone grafts have been as to the collagenized porcine xenografts (CPX) [30-33], it is a lack of relevant research on anorganic porcine xenograft materials compared to CPX or DBBM. To expand the choice of bone grafts in dental applications, therefore, we conducted the in vitro and in vivo evaluation of porcine-derived xenografts in comparison with bovine-derived xenografts.

In our SEM observation, both Bone-XP and Bio-Oss groups exhibited similar naturally rough surfaces. The surface roughness of material influences cell morphology, behavior, and adhesion [34]. Hatano et al. [35] reported that osteogenic cells grown on the micro-rough surface showed higher proliferation, ALP activity, and osteogenic gene expression in comparison with cells on the smooth surface. Therefore, the micro-rough surfaces of Bone-XP and Bio-Oss are considered to be favorable to adherence and proliferation of osteogenic cells. 
MSCs can differentiate into cells of the mesodermal lineage, such as adipocyte, osteocyte, and chondrocyte, etc. The proliferative and osteogenic characteristics of MSCs are used for reconstructing bone defects in clinical conditions [36,37]. Previous studies demonstrated that Bio-Oss has a positive effect on the osteogenic ability of the hMSCs [38]. In this study, hMSCs were used to evaluate the osteogenic activity of Bone-XP in comparison with the Bio-Oss. The cells cultured on the two different extracts of bone grafts showed no significant effect in terms of their cytotoxicity and proliferation rate. Upon osteogenic differentiation, both investigated extracts showed significant increases compared to control untreated cells. To determine the mechanism of osteogenic induction by the investigated extracts, we examined the related gene expressions by quantitative PCR (qPCR). In bone, ALP is localized on the entire cell surface of pre-osteoblasts and has long been used as an osteoblastic marker $[39,40]$. OPN, a secreted matrix glycoprotein, is biosynthesized by preosteoblast, osteoblast, osteocytes and plays a significant role in the bone remodeling procedure [41,42]. RUNX2, a key transcription modulator, is the main transcription factor for osteoblast differentiation and bone formation. In our study, both extracts of experimental xenografts induced ALP, OPN, and RUNX2 expressions in comparison to the control, but there was no significant difference between investigated extracts. The results of osteogenic differentiation and gene expression suggest that the Bone-XP is an osteoinductive material and can be used as a replacement for the Bio-Oss.

From a surgical standpoint of our in vivo experiment, Bone-XP gave favorable handling properties similar to Bio-Oss and could be easily implanted into the bone defects. In the study on the physicochemical property of porcine-derived bone which is essentially identical grafts with Bone-XP [1], the porcine-derived xenografts showed higher wettability than that of bovine-derived xenografts (Bio-Oss). High wettability of biomaterial can beneficially effect protein adsorption and cellular behavior $[1,43]$. In our surgical procedure, Bone-XP was easily wetted by body fluid after transplantation as well and it can be considered that Bone-XP is a relatively hydrophilic bone graft material.

This study conducted $\mu \mathrm{CT}$, histologic, and histometric evaluations to compare the new bone formation between the porcine-derived and bovine-derived xenografts in a critical-sized rat calvarial defect. Osteoblast from the defect margin utilizes the grafted bone substitute as a frame upon which to regenerate bone [44]. The newly formed bone should replace bone grafts as the latter resorbs during the healing period. In our histological analysis, the lines of osteoblast were easily observed surrounding the grafted xenografts in all groups, and this indicates that both xenografts used in this study have an excellent osteoconductivity [45]. Furthermore, in the result of the volumetric and histometric analysis, Bone-XP and Bio-Oss group induced comparable proportions of new bone regeneration at all the time points of 4 and 8 weeks. These results demonstrated that Bone-XP has the non-inferior capacity of new bone regeneration compared to that of Bio-Oss.

Based on the results obtained in the present study, Bone-XP ${ }^{\circledR}$, recently commercially available porcine xenograft, is a biocompatible, osteoinductive, and osteoconductive bone substitute in comparison with Bio-Oss ${ }^{\circledR}$. However, this in vivo study was conducted using limited sample size and observation time points, and therefore future preclinical trials using large animal and clinical trials are needed to verify these results.

\section{Conclusions}

Within the limitations of the present study, it can be concluded that the newly investigated porcine-derived bone substitute, Bone- $\mathrm{XP}{ }^{\circledR}$, may offer a favorable cell response and bone regeneration similar to those of commercial bovine bone mineral.

Author Contributions: Conceptualization, J.-B.H.; Data curation, E.-B.B., H.-J.K. (Ha-Jin Kim), J.-J.A. and H.-Y.B.; Formal analysis, E.-B.B., H.-J.K. (Ha-Jin Kim), J.-J.A. and H.-Y.B.; Investigation, E.-B.B., H.-J.K. (Ha-Jin Kim), J.-J.A. and H.-Y.B.; Methodology, H.-J.K. (Hyung-Joon Kim) and J.-B.H.; Supervision, H.-J.K. (Hyung-Joon Kim) and J.-B.H.; Writing-original draft, E.-B.B., H.-J.K. (Ha-Jin Kim) and J.-J.A.; Writing-review and editing, E.-B.B., H.-J.K. (Hyung-Joon Kim) and J.-B.H. 
Funding: This study was supported by the National Research Foundation of Korea (NRF) grant funded by the Korean government (MSIP) (2017R1A2B4005820) and was supported by a grant of the Korea Health Technology R\&D Project through the Korea Health Industry Development Institute (KHIDI), funded by the Ministry of Health \& Welfare, Republic of Korea (grant number: HI17C2397).

Conflicts of Interest: The authors declare no conflict of interest.

\section{References}

1. Lee, J.H.; Yi, G.S.; Lee, J.W.; Kim, D.J. Physicochemical characterization of porcine bone-derived grafting material and comparison with bovine xenografts for dental applications. J. Periodontal Implant Sci. 2017, 47, 388-401. [CrossRef] [PubMed]

2. Venkataraman, N.; Bansal, S.; Bansal, P.; Narayan, S. Dynamics of bone graft healing around implants. J. Int . Clin. Dent. Res. Organ. 2015, 7, 40.

3. Bauer, T.W.; Muschler, G.F. Bone graft materials: An overview of the basic science. Clin. Orthop. Relat. Res. 2000, 371, 10-27. [CrossRef]

4. Misch, C.M. Autogenous bone: Is it still the gold standard? Implant Dent. 2010, 19, 361. [CrossRef]

5. van den Bergh, J.P.; ten Bruggenkate, C.M.; Krekeler, G.; Tuinzing, D.B. Sinus floor elevation and grafting with autogenous iliac crest bone. Clin. Oral Implant. Res. 1998, 9, 429-435. [CrossRef]

6. Cypher, T.J.; Grossman, J.P. Biological principles of bone graft healing. J. Foot Ankle Surg. 1996, 35, $413-417$. [CrossRef]

7. Jensen, S.S.; Terheyden, H. Bone augmentation procedures in localized defects in the alveolar ridge: Clinical results with different bone grafts and bone-substitute materials. In Database of Abstracts of Reviews of Effects (DARE): Quality-Assessed Reviews [Internet]; Centre for Reviews and Dissemination (UK): York, UK, 2009.

8. Jensen, S.; Bosshardt, D.; Buser, D. Bone grafts and bone substitute materials. Buser D Ed. 2009, 20, 1-96.

9. Jensen, T.; Schou, S.; Stavropoulos, A.; Terheyden, H.; Holmstrup, P. Maxillary sinus floor augmentation with Bio-Oss or Bio-Oss mixed with autogenous bone as graft: A systematic review. Clin. Oral Implant. Res. 2012, 23, 263-273. [CrossRef]

10. Pang, K.M.; Um, I.W.; Kim, Y.K.; Woo, J.M.; Kim, S.M.; Lee, J.H. Autogenous demineralized dentin matrix from extracted tooth for the augmentation of alveolar bone defect: A prospective randomized clinical trial in comparison with anorganic bovine bone. Clin. Oral Implant. Res. 2017, 28, 809-815. [CrossRef]

11. Pinholt, E.M.; Bang, G.; Haanaes, H.R. Alveolar ridge augmentation in rats by Bio-Oss. Eur. J. Oral Sci. 1991, 99, 154-161. [CrossRef]

12. Haas, R.; Mailath, G.; Dörtbudak, O.; Watzek, G. Bovine hydroxyapatite for maxillary sinus augmentation: Analysis of interfacial bond strength of dental implants using pull-out tests. Clin. Oral Implant. Res. 1998, 9, 117-122. [CrossRef]

13. Berglundh, T.; Lindhe, J. Healing around implants placed in bone defects treated with Bio-Oss $($. An experimental study in the dog. Clin. Oral Implant. Res. 1997, 8, 117-124. [CrossRef]

14. Noumbissi, S.S.; Lozada, J.L.; Boyne, P.J.; Rohrer, M.D.; Clem, D.; Kim, J.S.; Prasad, H. Clinical, histologic, and histomorphometric evaluation of mineralized solvent-dehydrated bone allograft (Puros) in human maxillary sinus grafts. J. Oral Implantol. 2005, 31, 171-179. [CrossRef]

15. Gill, D.S.; Tredwin, C.J.; Gill, S.K.; Ironside, J.W. The transmissible spongiform encephalopathies (prion diseases): A review for dental surgeons. Int. Dent. J. 2001, 51, 439-446. [CrossRef] [PubMed]

16. Salamanca, E.; Lee, W.-F.; Lin, C.-Y.; Huang, H.-M.; Lin, C.-T.; Feng, S.-W.; Chang, W.-J. A novel porcine graft for regeneration of bone defects. Materials 2015, 8, 2523-2536. [CrossRef]

17. Feng, W.; Fu, L.; Liu, J.; Li, D. The expression and distribution of xenogeneic targeted antigens on porcine bone tissue. Transplant. Proc. 2012, 44, 1419-1422. [CrossRef] [PubMed]

18. Bracey, D.; Seyler, T.; Jinnah, A.; Lively, M.; Willey, J.; Smith, T.; Van Dyke, M.; Whitlock, P. A Decellularized Porcine Xenograft-Derived Bone Scaffold for Clinical Use as a Bone Graft Substitute: A Critical Evaluation of Processing and Structure. J. Funct. Biomater. 2018, 9, 45. [CrossRef]

19. Ramírez-Fernández, M.; Calvo-Guirado, J.L.; Delgado-Ruiz, R.A.; Maté-Sánchez del Val, J.E.; Vicente-Ortega, V.; Meseguer-Olmos, L. Retracted: Bone response to hydroxyapatites with open porosity of animal origin (porcine [OsteoBiolßmp3] and bovine [Endobon $囚]$ ): A radiological and histomorphometric study. Clin. Oral Implant. Res. 2011, 22, 767-773. [CrossRef] 
20. Go, A.; Eun Kim, S.; Mi Shim, K.; Lee, S.M.; Hwa Choi, S.; Sik Son, J.; Soo Kang, S. Osteogenic effect of low-temperature-heated porcine bone particles in a rat calvarial defect model. J. Biomed. Mater. Res. Part A 2014, 102, 3609-3617. [CrossRef]

21. Yung, G.P.; Schneider, M.K.; Seebach, J.D. Immune responses to $\alpha 1,3$ galactosyltransferase knockout pigs. Curr. Opin. Organ Transplant. 2009, 14, 154-160. [CrossRef]

22. Park, S.-A.; Shin, J.-W.; Yang, Y.-I.; Kim, Y.-K.; Park, K.-D.; Lee, J.-W.; Jo, I.-H.; Kim, Y.-J. In vitro study of osteogenic differentiation of bone marrow stromal cells on heat-treated porcine trabecular bone blocks. Biomaterials 2004, 25, 527-535. [CrossRef]

23. Linde, F.; Hvid, I.; Pongsoipetch, B. Energy absorptive properties of human trabecular bone specimens during axial compression. J. Orthop. Res. 1989, 7, 432-439. [CrossRef] [PubMed]

24. Gao, Y.; Cao, W.-L.; Wang, X.-Y.; Gong, Y.-D.; Tian, J.-M.; Zhao, N.-M.; Zhang, X.-F. Characterization and osteoblast-like cell compatibility of porous scaffolds: Bovine hydroxyapatite and novel hydroxyapatite artificial bone. J. Mater. Sci. Mater. Med. 2006, 17, 815-823. [CrossRef] [PubMed]

25. Nazirkar, G.; Singh, S.; Dole, V.; Nikam, A. Effortless effort in bone regeneration: A review. J. Int. Oral Health 2014, 6, 120. [PubMed]

26. An, K.C.; Choi, J.S.; Kim, T.H.; Lee, Y.J.; Yoon, T.L.; Shin, J.W.; Chung, H.J.; Kim, S.W. Biocompatibility Evaluation of Heat-treated Mineralized Porcine Cancellous Bone: Using Animal \& Clinical Study. J. Korean Orthop. Res. Soc. 2009, 12, 33.

27. Park, E.S.; Yu, J.A.; Choi, S.H.; Lee, D.W. Ridge preservation using porcine bone mineral and cross-linked collagen membrane in damaged socket: A case report. J. Korean Acad. Osseointegr. 2017, 9, 1-6.

28. Lee, D.-W.; Pi, S.-H.; Lee, S.-K.; Kim, E.-C. Comparative histomorphometric analysis of extraction sockets healing implanted with bovine xenografts, irradiated cancellous allografts, and solvent-dehydrated allografts in humans. Int. J. Oral Maxillofac. Implant. 2009, 24, 609-615.

29. Wood, R.A.; Mealey, B.L. Histologic comparison of healing after tooth extraction with ridge preservation using mineralized versus demineralized freeze-dried bone allograft. J. Periodontol. 2012, 83, 329-336. [CrossRef]

30. Scarano, A.; Lorusso, F.; Ravera, L.; Mortellaro, C.; Piattelli, A. Bone regeneration in iliac crestal defects: An experimental study on sheep. Biomed Res. Int. 2016, 2016. [CrossRef]

31. Calvo-Guirado, J.L.; Gómez-Moreno, G.; Guardia, J.; Ortiz-Ruiz, A.; Piatelli, A.; Barone, A.; Martínez-González, J.M.; Meseguer-Olmo, L.; López-Marí, L.; Dorado, C.B. Biological response to porcine xenograft implants: An experimental study in rabbits. Implant Dent. 2012, 21, 112-117. [CrossRef]

32. Iezzi, G.; Degidi, M.; Piattelli, A.; Mangano, C.; Scarano, A.; Shibli, J.A.; Perrotti, V. Comparative histological results of different biomaterials used in sinus augmentation procedures: A human study at 6 months. Clin. Oral Implant. Res. 2012, 23, 1369-1376. [CrossRef] [PubMed]

33. Scarano, A.; Piattelli, A.; Assenza, B.; Quaranta, A.; Perrotti, V.; Piattelli, M.; Iezzi, G. Porcine bone used in sinus augmentation procedures: A 5-year retrospective clinical evaluation. J. Oral Maxillofac. Surg. 2010, 68, 1869-1873. [CrossRef] [PubMed]

34. Chang, H.-I.; Wang, Y. Cell responses to surface and architecture of tissue engineering scaffolds. In Regenerative Medicine and Tissue Engineering-Cells and Biomaterials; InTechOpen: London, UK, 2011.

35. Hatano, K.; Inoue, H.; Kojo, T.; Matsunaga, T.; Tsujisawa, T.; Uchiyama, C.; Uchida, Y. Effect of surface roughness on proliferation and alkaline phosphatase expression of rat calvarial cells cultured on polystyrene. Bone 1999, 25, 439-445. [CrossRef]

36. Cooper, L.; Harris, C.; Bruder, S.; Kowalski, R.; Kadiyala, S. Incipient analysis of mesenchymal stem-cell-derived osteogenesis. J. Dent. Res. 2001, 80, 314-320. [CrossRef]

37. Jafarian, M.; Eslaminejad, M.B.; Khojasteh, A.; Abbas, F.M.; Dehghan, M.M.; Hassanizadeh, R.; Houshmand, B. Marrow-derived mesenchymal stem cells-directed bone regeneration in the dog mandible: A comparison between biphasic calcium phosphate and natural bone mineral. Oral Surg. Oral Med. Oral Pathol. Oral Radiol. Endodontol. 2008, 105, e14-e24. [CrossRef]

38. Yu, B.-H.; Zhou, Q.; Wang, Z.-L. Periodontal ligament versus bone marrow mesenchymal stem cells in combination with Bio-Oss scaffolds for ectopic and in situ bone formation: A comparative study in the rat. J. Biomater. Appl. 2014, 29, 243-253. [CrossRef]

39. Liu, S.; Liu, D.; Chen, C.; Hamamura, K.; Moshaverinia, A.; Yang, R.; Liu, Y.; Jin, Y.; Shi, S. MSC transplantation improves osteopenia via epigenetic regulation of notch signaling in lupus. Cell Metab. 2015, 22, 606-618. [CrossRef] 
40. Liu, W.; Liu, Y.; Guo, T.; Hu, C.; Luo, H.; Zhang, L.; Shi, S.; Cai, T.; Ding, Y.; Jin, Y. TCF3, a novel positive regulator of osteogenesis, plays a crucial role in miR-17 modulating the diverse effect of canonical Wnt signaling in different microenvironments. Cell Death Dis. 2013, 4, e539. [CrossRef]

41. Nilsson, S.K.; Johnston, H.M.; Whitty, G.A.; Williams, B.; Webb, R.J.; Denhardt, D.T.; Bertoncello, I.; Bendall, L.J.; Simmons, P.J.; Haylock, D.N. Osteopontin, a key component of the hematopoietic stem cell niche and regulator of primitive hematopoietic progenitor cells. Blood 2005, 106, 1232-1239. [CrossRef]

42. Grassinger, J.; Haylock, D.N.; Storan, M.J.; Haines, G.O.; Williams, B.; Whitty, G.A.; Vinson, A.R.; Be, C.L.; Li, S.; Sørensen, E.S. Thrombin-cleaved osteopontin regulates hemopoietic stem and progenitor cell functions through interactions with $\alpha 9 \beta 1$ and $\alpha 4 \beta 1$ integrins. Blood 2009, 114, 49-59. [CrossRef]

43. Kubies, D.; Himmlová, L.; Riedel, T.; Chánová, E.; Balík, K.; Douderova, M.; Bártová, J.; Pesakova, V. The interaction of osteoblasts with bone-implant materials: 1 . The effect of physicochemical surface properties of implant materials. Physiol. Res. 2011, 60, 95. [PubMed]

44. Laurencin, C.; Khan, Y.; El-Amin, S.F. Bone graft substitutes. Expert Rev. Med Devices 2006, 3, 49-57. [CrossRef] [PubMed]

45. Kumar, P.; Vinitha, B.; Fathima, G. Bone grafts in dentistry. J. Pharm. Bioallied Sci. 2013, 5, S125. [CrossRef] [PubMed]

(C) 2019 by the authors. Licensee MDPI, Basel, Switzerland. This article is an open access article distributed under the terms and conditions of the Creative Commons Attribution (CC BY) license (http://creativecommons.org/licenses/by/4.0/). 